\title{
Terapia Comunitária como Instrumento de Humanização e Cuidado no Sistema Único de Saúde
}

Tovar, Juliana Eller; Almeida, Jose Jonathas A. de; Sousa, Elaine Freitas de; Santos, Nivea Adriana de Santana; Rocha, Silmara Alves Moreira; Cavalcante, Juliana Brito; Santos, Monick Forte

Escola de Saúde Publica do Estado do Ceara ESP-CE — pazpelavida@yahoo.com.br

A terapia comunitária é um tipo de tecnologia de cuidado que surgiu em 1987 na comunidade do Pirambu, em fortaleza ceará. Sendo uma ferramenta que abre um grande espaço de acolhimento, constituindo um ambiente de escuta, entendimento, reflexão e troca de experiência e vivencia de saberes que fortalece o vinculo dos profissionais com a comunidade e meio social fortalecendo o processo de humanização. Buscando respostas, soluções e apoio para os problemas encontrados no meio pessoal junto com a comunidade sendo um instrumento que ao mesmo tempo desenvolver o processo de cuidado faz o processo de humanização dentro do senário do sistema único de saúde, fazendo com que esse processo se espalhou por todo o Brasil. Hoje existe mais de 7 mil terapeutas comunitários que desenvolver uma assistência e cuidados a um grande número de pessoas. o objetivo deste trabalho é mostrar a importância e resultados que a terapia comunitária traz no processo de humanização profissional e cuidado, como também relatar e fortalecer o seu uso. a metodologia desta pesquisa é do tipo exploratória, de caráter bibliográfico realizada no período de Janeiro de 2014 através de acervos disponíveis em bibliotecas, artigos científicos (scielo, 4shared) e bancos de dados da internet, sendo feito uma triagem dos textos publicados entre 2009 a 2014. Os textos foram analisados e adequados ao tema proposto mediante leituras sucessivas e fichamentos dos materiais selecionados para extrair reflexões sobre a temática em pauta. a terapia comunica intriga os participantes a interagir e descobri no grupo a importância do envolvimento do outro na resolução dos problemas, desenvolvendo o poder de cada participante de forma humanizada para enfrentar suas dificuldades e agir no processo de cuidado. Respeitando os seu valores, crenças, potencializando as suas esperanças, resgatando a autonomia dos profissionais e comunidade a través da humanização que é gerada consequentemente, fazendo valer toda a cultura local e ocasionando um processo de mudança assistencial humanizado com benefícios associado da terapia comunitária no processo de cuidado. Dispondo um resultado satisfatório a quem faz uso e conduz reduzindo custos aos gestores e uso de medicação, melhorando a qualidade de vida dos usuários e profissionais de saúde. Sabe-se que a terapia comunitária consegue gera resultados importantes e desencadear o processo de humanização no processo de cuidado, melhorando a qualidade de vida do usuário e profissionais no sistema único de saúde a baixo custo em decorrência de um trabalho diferenciado, sendo importante o seu fortalecimento e ampliação desta atividade.

Tovar, Juliana Eller; Almeida, Jose Jonathas A. de; Sousa, Elaine Freitas de; Santos, Nivea Adriana de Santana; Rocha, Silmara Alves Moreira; Cavalcante, Juliana Brito; Santos, Monick Forte. Terapia Comunitária como Instrumento de Humanização e Cuidado no Sistema Único de Saúde.. In: Anais do Congresso Internacional de Humanidades \& Humanização em Saúde [= Blucher Medical Proceedings, num.2, vol.1]. São Paulo: Editora Blucher, 2014. ISSN 2357-7282

DOI 10.5151/medpro-cihhs-10855 